УДК 165.4

\title{
The Limits of True Knowledge (Metaphysical and Topological Aspects)
}

\author{
Alexander K. Sekackiy* \\ Saint Petersburg State University \\ 7-9 Universitetskaya nab., Saint Petersburg, 199034, Russia
}

Received 01.07.2015, received in revised form 12.09.2015, accepted 02.10.2015

\begin{abstract}
The present article studies the correlation of true cognition not with the performance of certain cognitive or probative procedures by a subject, but with the processes occurring to the object of cognition. Therefore, the limits of truth coincide with the inexhaustible regularity or with nature in the antique, or Kant's interpretation. Opposite to science, art deals with principal singularity: its objects remain the objects of art as long as "they cannot be confused with anything else".

The present article considers some "illegal" cognitive intrusions, both "leftwards" from the limits of truth where the quantum objects (ensembles) are found, and "rightwards", where the definiteness of the subject and the soul itself are determined.
\end{abstract}

Keywords: Limits of truth, singularity, quantum objects.

DOI: 10.17516/1997-1370-2015-8-11-2614-2620.

Research area: philosophie.

The question of the criteria of truth is one of the most developed ones in European metaphysics and in the philosophy of science. Nevertheless, the angle of view often seems to be quite stereotypical: knowledge bears certain consequences for the knowers; these are the consequences that are the first interest for epistemology as a theory of cognition as such. According to this setup (classification of consequences for the knowers) it is a custom to differentiate between the deep and superficial knowledge, the priority of truth to delusion and other truly important things. The development of knowledge and the advancement of science (and technology) have also been considered from the knowers' point of view. But what if we take a look from the position of the object of cognition, of the thing exposed to cognition?

Would it be fair to claim that true knowledge is not a significant event for the most "truly cognized", for it does not, as any other sort of knowledge that remains knowledge, change anything in the object of cognition? If the process of cognition required digging in the totality of the cognized objects, it would have been different; but fortunately, the cognition efforts do not change anything in the object of cognition. Therefore, it means that knowledge bears a homeopathic character, while the supreme truth is transcendent.

(C) Siberian Federal University. All rights reserved

* Corresponding author E-mail address: aksek@inbox.ru 
And still, it is also appropriate to put this the following way: is the cognition occurring "to" an object equally harmless to it? If we ask this question, it becomes clear that it is not; a part of nature is the only thing that is not deprived of anything by being under cognition, and this is the only space that we can still call the limits of truth.

There's the next statement coming up. The glancing contactless reflection does not cover the being all over, but only penetrates "from here to here", covering only the things that are anyhow relevant for cognition and called nature; that sounds pretty much Kant-like. Consequently, beyond the mentioned limits the truth changes its status if it ever remains the truth, which is a great food for thought.

Now it is appropriate to apply the common topographic division of the possible truth limits.

On the "left side", or beyond one edge of physis, there is the so-called microworld, and it is not there completely. In reality it is one more "under-space", where the being, speaking in Hegel's style, is not totally correlated to itself and does not even possess the advantage of simple presence. And once it is so, the truth here is not formed yet; it still lacks the "sublation", or Aufheben.

Following the description provided by quantum mechanics, we witness some exquisite objects: quantum ensembles, superpositions, quantum entanglement and even the preliminary classification of such are yet to come (Claude Cohen-Tannoudji, Bernard Diu, Frank Lapoe, 2000). But the cognitive effort applied to them turns into decoherence, after which the objects of $(\mathrm{n} \uparrow, \mathrm{n} \downarrow)$ ) type do not longer remain the same, but disintegrate, losing their previous completeness forever. ${ }^{1}$

This is what it is like to the left from the stable universum, when the "multiversum" has already been stopped in its endless divergence, but the truth has not been set and there is no stable being for it, because there is nothing that can be harmlessly measured yet.

Beyond the right limit knowledge loses its neutrality to the extent to which its objects turn into subjects. Here any "bringing out to the open", revelation, smelling around etc. cause ontological harm to the subject, destroying its completeness. When a subject's little shameless secret becomes known to anyone else, it turns out to cause ontological harm to itself, and sometimes the harm is irreparable.

Only that which is not directly denatured by cognition is called nature. It seems to be a nice additional definition to the "world of regularities and repetitions", i.e. to the firmly fixed and welltempered universum; it is exactly the thing that is penetrated by glancing reflection non-stop so lightly that every subsequent cognitive effort finds the object of cognition in the same state as previously. That is why the truth does not resist any tests; everything that has been counted can be counted over and over again, but it is only true when spoken of nature, of substance. It is easy to notice that both criteria of Popper, verification and falsification, comply with this principle. The latter requires the indication of a situation, let's say, of the ultimate experiment, a certain result of which proves a theory false. But if a cognitive effort and an experiment in particular are able to change the structure of the cognized, such requirement loses its sense. Because even though the dimensions of a table can be measured over and over again, it is not true for Schrödinger's cat. Together with the limits of truth, the limits of substance are defined: on one side, there is the simple supernatural, while the so-called "undernatural" remains on the other.

So, the question on whether the world is cognizable or not, should be answered as follows: yes, to the extent it is not destructed by any measurements and other cognitive efforts. Of 
course, here one can speak of a weird paradox: as though, asking whether a mushroom is edible or not, one gets the answer that it is edible to the extent it is protected from being eaten. Though it seems funny, this is exactly how it is with the cognizable world. It means that either the world is so radically different from a mushroom, which is hardly true, or cognition has nothing in common with eating, which is something we have to admit. We also have to assume that cognition is a sort of "anti-interaction" while truth is the edibility of the mushrooms that have not been eaten. Therefore the limits of truth obtain some additional determination.

If so, the truth is also a function of time, or, to be more precise, of chronopoesis; it does not become possible and determined at once. At first it requires the performance of some essential tautologies, of a massive decoherence, and only after that the thereby fixed universum is considered protected from any changes and cognitive procedures from outside.

The consciousness born from the second explosion of semiosis is still too young and therefore unprotected against measurements, let alone "investigations". Those are only simple objects of [ $\mathrm{n}$ is $\mathrm{n}$ ] type that can be measured harmlessly; fortunately, that is what the so-called macroworld predominantly consists of, but the quantum ensembles ( $\mathrm{n} \uparrow, \mathrm{n} \downarrow$ ) and the subjects having souls get lost or transformed as a result of the changes.

It brings us to some curious conclusions of both practical and metaphysical kind. Thus, if "nature" is an oasis of harmless measurability and it is the only reason why true cognition is possible in its regard, then the "world of the done" is something like a reserve within a reserved nature (Mamardashvili M.K., 1984). The done is the limited territory of the truth, as within its limits it is possible to measure and reproduce as much as one wishes: the object are cut out for this.
That is why Mamardashvili was right when he said that it is not the done that we cognize, but it is by means of the done that we do it: for example, we search for the analogues of the done in nature and measure them like the things from the human everyday life. Mature nature is exposable to such procedures, as it has the set limit of truth, though the reference of truth is beyond it.

Art has a different status: it is different and it has to be dramatically different from the done; it is not "man-made". In his time Yu.M. Lotman emphasized that the basis of art is the function of determining selection (i.e. the Einselection which forms the self-identical being from the divergence of worlds). A stump found in the forest and withdrawn from the forest is, therefore, an object of art per se; the duration of its "adjustment" depends on nothing but some historical circumstances. If a computer could generate a free flow of word combinations, the poet (artist) would be the one who could extract the necessary ones as it makes no difference where to get them from, from the vague memory experience or a spontaneous flow of words (Lotman Yu., 2007).

However, there is one principal moment the elimination of which eliminates art as well. That is: the selected object remains singular. Unlike logic, poetry does not point at any conditions under which the same object would have been created. So to say, such conditions disappear at the moment of extraction, and it is the only reason that makes the object of art happen. As for true knowledge, it can be considered accomplished only if the conditions of obtaining it do not disappear.

The paradox of singularity in art is comparable to wave-particle duality. Here is an object of art, for example, a sculpture in a city park. First of all, this object is not separated from non-art: the paths leading to it, the ice-cream wraps and rocks, the grass around it are not art. This far, the conditions for truth and art are the 
same. But being an object of art, the sculpture is singular: if we find it in another park, and then in a third one and in any park in general, it will not be an object of art anymore: it will be considered to be a simple attribute of park like grass, trees and paths. As for truth, the opposite is right: if we do not find the truth surrounded by the same environment, if we come across it only from time to time, it cannot be considered truth at all. This is the difference of the fine (the beauty) from the objective truth.

However, these are not all the difficulties and oddities. The analogue of the light interference picture is the two incompatible yet inseparable effects: non-reduceability and distribution, so Walter Benjamin did the same in art studies as Bohr and Heisenberg in nature research. Let us think of the following. It is possible to eliminate a piece of art in two ways: either to erase it from the face of the earth (from the memory) or copy and distribute it. It sounds clear as both of them kill the singularity. The answer to the question which of the ways is more radical is not so easy to find.

Physical destruction of a singular object seems irreparable: there is a bitter list of irretrievably lost masterpieces. However, the phenomenon of a gaping hole calling for restoration activates some wave function of art: the search for the lost singularity is just the same business for an artist as creation of a new one. Moreover, that may be the lost singularity that cannot be eliminated by means of distribution as the restoration versions.

Reproductions are a different matter. Here is Pushkin doing his capturing, presenting as a singular object, a poem:

\footnotetext{
A magic moment I remember:

I raised my eyes and you were there,

A fleeting vision, the quintessence

Of all that's beautiful and rare.
}

This was addressed to Anna Kern, thereby revealing and immortalizing her singularity. She is the only woman, the image and the cause of it; she is the lost physical singularity that has not left the poetic singularity no matter how many times the poem is re-typed: it never loses its sacred power. But let us suppose that a biographer of Pushkin discovers that the poet had a custom to send this very poem to any conquered woman after an erotic act: "A magic moment I remember" etc. Would the poetic power still linger in these lines? In the event of true knowledge the truth would, no doubt, have been served with more and more of new confirmations. But art lives beyond the limits of truth of the knowers, therefore this paradox is only resolved with laughter, because it is the laughter that accompanies destruction of such a work of art. Thereby we reveal another important peculiarity of truth: it may be shining, stunning, sad, severe, stubborn, but it seems like truth can never be funny...

So what is art going through in the era of technical reproduction? First of all, distinctive stratification. A great number of objects fallout from the scope of art for lacking singularity along with all the possible features of beauty. For example, that is what happens with all the fashion jewellery of the world, a scattering of unique objects, where the equal and all and the same coincide. In some other cases the difference of the original from its copies is maintained: here we could say that all copies are just printouts, while the original in its legal appearance is nothing but a privileged printout, like the one we cannot point at. This is where the stored art and created art makeup different echelons: instead of an object of art we get a copy or a sample, but it only means that the new, created work of art will be recognized as such only when it deserves being copied, considering that every copy is not a work of art any more. 
Now it is the time to think on the three

integrated questions altogether:

Is the mushroom edible?

Is the world cognizable?

Is a work of art unique?

I believe the sequence of answers is the following. The mushroom is edible if it has ever been eaten: i.e. if it has been consumed as an object and nothing happened to the subject. The world is cognizable if after the applied cognition efforts it remained unchanged (and the new act of cognition finds it in the same form) and the subject has changed into the knower.

A work of art is unique if the efforts of reproduction (something between consumption and cognition) are applied to it, and the obtained results, no matter the number, do not abolish the ontological status of the original.

It opens space for a great number of remarks, for example: the world can remain cognizable even if it is not being cognized, if the act of cognition is deposited in such a way that it will occur sooner or later. But a work of art cannot remain unique (and even remain art) if it is not copied at least on the level of perception. I.e. its involvement in temporal relations is set in a stricter way.

Moving further, let us study the frontier cases of non-copying and copying of art, that transform singularity into regularity. Art is found in between them, i.e., like truth, art has its limits. On the left there is the "non-art" recognized as such for the reason of its "unartfulness', such as graphomania, cacophony, kitsch... Such opuses are not copied or reproduced at least because it never enters anyone's mind. On the right we deal with industry where copying destructs (eliminates) the singularity of the object, due to which, despite its "artfulness", the object, let it be earrings, stunningly beautiful wallpaper, an exquisite bag, remains nothing but "fashion jewellery".
Now the only thing that remains is to find out how these limits, truths and beauties correlate with each other. But first of all we need go deep into one mysterious circumstance: how can a reproduced work of art preserve its singularity? Because this paradox peculiarity is the feature that makes an object a work of art. The beautiful woolpack clouds are not classified as works of art just because they are not copyable, that is why it is only their image that can be a work of art, not themselves. The gods who could sculpt the woolpack and thunderous clouds would no doubt compete for the title of the best artist, but the question is, would us mortals be able to understand whether they are dealing with the originals or reproductions? One way or another, we see that the protection of a piece from profanatory copying is a convention. For the artist making gravures, for example, the originals are the first five prints; for a poet the layout original is a poem, for a composer it is a score; but here the list doubles and gets more confusing. What is it for a conductor? An actor? Or why is a work of a sound recording engineer not a work of art? This confusion does nothing but confirms the conventional nature of the right edge which, however, does not abolish the singularity limit itself, comparable to the limits of truth, but simultaneously incomparable to it.

With all these differences and oppositions we get two mushrooms that seem edible for the reason of their "uneatenness"; the truth is inexhaustible regularity, and art is inexhaustible singularity. It is also important to remark that the regularity and singularity themselves can also be exhaustible. Thus, the routine human life happens in its simple exhaustible regularity and the exhaustible singularity of presence. It is thereby unartful and untruthful as a whole, but it is what the miracle of vitality is about.

The situation changes if we draw a dividing range within the scope of cognitive efforts. The 
result of applying such cognitive efforts in general is the multiplication of inexhaustible regularity, as our knowledge differs from the objects of nature with at least the same unwearability. Let us compare the two theses:

1. No matter how much the Earth attracts the Moon, it won't hurt the Moon.

2. No matter how much a word taken from a dictionary is used in these or those contexts, it is not threatened with exhaustion.

The second statement looks even more evident: if in the process of attraction the mutually attracted objects together with attraction itself may be somehow consumed, then in the process of signification, the sign retains its meaning without consuming it: therefore, it is the only case where the true and inexhaustible regularity is reached. However, if we speak of the effort of the cognition subject, of the effort applied by ego cogito, the regularity is violated, and the violation is principal. Let us say so: credibility is built with the method of approaching, by means of assimilation with the truth: but the thing is that the truth is not similar to itself. Just like the happening of comprehension, the first-person cognition, the truth needs to occur as though it occurs for the first time: no matter what inexhaustible regularity it discovers, the truth has to remain my personal singularity, otherwise the happening of cognition will never happen. In other words, the true cognition, changing nothing in the cognized, radically changes the knower himself, and without the satisfaction of these two conditions the true cognition (cognition of the truth) is impossible.

The Einselection procedure, i.e. determined selection (selection for cognition, for example), brings to "breaking the completeness" of the object. The favourite example of such in quantum mechanics is Schrödinger's cat.

\section{References}

Cohen-Tannoudji C., Diu B., LapoeF. Kvantovaia mekhanika [Quantum mechanics]. Yekaterinburg, 2000.

Lotman Iu.M. Iskusstvo kak informatsionnyi paradoks [Art as informational paradox]. Moscow, 2007.

Mamardashvili I.K. Klassicheskii i neklassicheskii ideal ratsional'nosti [Classic and non-classic ideals of rationality]. Moscow, 1984. 


\title{
Границы истинного познания \\ (Метафизический и топологический аспект)
}

\author{
А.К. Секацкий \\ Санкт-Петербургский государственный университет \\ Россия, 199034, Санкт-Петербург \\ Университетская наб., 7-9
}

В статье рассматривается зависимость истинного познания не от выполнения субъектом определенных познавательных или доказательных процедур, а от того, что происходит с предметом познания, с познаваемым. Тем самым диапазон истины совпадает с неисчерпаемой регулярностью или с природой в античном и кантовском понимании этого слова. $B$ противоположность науке искусство имеет дело с принципиальной сингулярностью, его объекты остаются объектами искусства до тех пор, пока их «невозможно спутать ни с чем другим».

В данной работе рассматриваются и «незаконные» познавательные вторжения - как влево от диапазона истины, где находятся квантовые объекты (ансамбли), так и «вправо», где заданы определенность субъекта и сама душа.

Ключевые слова: диапазон истины, сингулярность, квантовые объектыл.

Научная специальность: 09.00.00. - философские науки. 